\title{
The Role of Genipin and Geniposide in Liver Diseases: A Review
}

\author{
Sheng-xi Meng ${ }^{1,2}$, Jing-hua Peng ${ }^{1,2,5}, \mathrm{Qin} \mathrm{Feng}^{1,2}$, Jian-mei $\mathrm{CaO}^{4}$ and Yi-yang $\mathrm{Hu}^{1-3 *}$
}

${ }^{1}$ Institute of Liver Diseases, Shuguang Hospital Affiliated to Shanghai University of Traditional Chinese Medicine, Shanghai 201203, China

${ }^{2}$ Key Laboratory of Liver and Kidney Diseases (Shanghai University of Traditional Chinese Medicine), Ministry of Education, Shanghai 201203, China

${ }^{3} E$-institute of Traditional Chinese Internal Medicine of Shanghai Municipal Education Commission, Shanghai 201203, China

${ }^{4}$ Shanghai University of Traditional Chinese Medicine, Shanghai 201203, China

${ }^{5}$ Shanghai Key Laboratory of Traditional Chinese Clinical Medicine

\begin{abstract}
Liver disease is characterized by inflammation and/or tissue damage that is serious enough to impair hepatic function. Tens of millions of patients are affected by liver diseases worldwide. Geniposide is an irioidglyco compound isolated from Gardenia fruits which has been used for many years in Chinese medicine for the treatment of hepatic disorders and inflammatory diseases. Genipin, the metabolite of geniposide, is a natural product present in fruit of Gardenia jasminoides. The relative bioactivity of genipin and geniposide has been widely reported in many studies and the potential application of these compounds in the treatment of liver diseases has come to light. This review summarizes current findings on the use of geniposide and genipin in the treatment of liver disease.
\end{abstract}

Keywords: Geniposide; Genipin; Liver diseases

Abbreviations: AAP: Acetaminophen; AFB1: Aflatoxin B1; AKP: Alkaline Phosphatase; ALT: Alanine Aminotransferase; AST: Aspartate Transaminase; AUC: Areas Under The Curve; BSP: Sulfobromophthalein; CAT: Catalase; $\mathrm{CCl}_{4}$ : Carbon Tetrachloride; CM: Canalicular Membrane; CMVs: Canalicular Membrane Vesicles; CYP: Cytochrome Oxidase; DPI: Diphenyleneiodonium; ECM: ExtraCellular Matrix; GalN: Galactosamine; GF: Gardenia Fruit; GLP-1: Glucagon-like peptide-1; GSH: Growth Stimulating Hormone; GSH-Px: GSH-peroxidase; GSSG: Glutathione (Oxidized); HCC: Hepatocellular Carcinoma; HPLC: High Performance Liquid Chromatography; HYP: Hydroxyproline; ICKT: Inchin-ko-to; IFN: Interferon; IL: Interleukin; JNK: Jun NH2-Terminal Kinase; LTC(4): Leukotriene C4; LPS: Lipopolysaccharide; MAPK: Mitogen-Activated Protein Kinase; MDA: Malondialdehyde; MPT: Mitochondrial Permeability Transition; Mrp2: multidrug Resistance-Associated Protein 2; MSG: Monosodium Glutamate; MTX: Methotrexate; NAC: N-acetyl-1cysteine; NAFLD: Non-Alcoholic Fatty Liver Disease; NASH: NonAlcoholic Steatohepatitis; NGF: Nerve Growth Factor; NO: Nitric Oxide; P-450: Cytochrome P-450; p-c-Jun: Phosphorylated c-Jun; P-gp: P-glycoprotein; PPARa: Peroxisome Proliferator-Activated Receptor- $\alpha$; ROS: Reactive Oxygen Species; SOD: Superoxide Dismutase; TC: Taurocholate; TLC-3S: Taurolithocholate-3-Sulfate; TRADD: TNF-R1 Associated Death Domain; TUNEL: Terminal Deoxynucleotidyl Transferase-Mediated Dutp Nick End Labeling; UCP: Uncoupling Protein; UDS: Unscheduled DNA Synthesis

\section{Introduction}

Liver disease is associated with hepatic inflammation, tissue damage and altered liver function, and affects tens of millions of patients worldwide [1]. Geniposide (Figure 1 left) is one of the main irioidglyco compounds isolated from Gardenia fruits and has been used for many years in Chinese medicine for treatment of hepatic disorders and inflammatory diseases [2]. Genipin (Figure 1 right), the metabolite of geniposide, is a natural product present in fruit of Gardenia jasminoides. Previous studies have shown that geniposide is transformed to genipin in the bowel, indicating that it may be the major form of geniposide in blood [3-6]. Geniposide is hydrolyzed to aglycone genipin by beta-Dglycosidases which are bacterial enzymes found in the intestines and the liver [7,8] (Figure 2).
Numerous studies have been undertaken to investigate the biological activity of genipin and geniposide, including its effect on protein modulation [9-11], as well as its anti-inflammatory $[5,12,13]$, anti-oxidative [5,14], immunosuppressive [15], antithrombotic [16], anti-angiogenic [5], anti-tumor [17-19] and neuroprotective effects [20-23].

\section{Metabolism and Pharmacokinetics}

The pharmacokinetics of geniposide, were investigated in a study that simultaneously estimated geniposide and genipin levels in mouse plasma after oral administration of Gardenia fruit [24]. Other studies have described the pharmacokinetics of geniposide after intravenous [25], and oral administration of Yin-Zhi-Ku decoction [26].
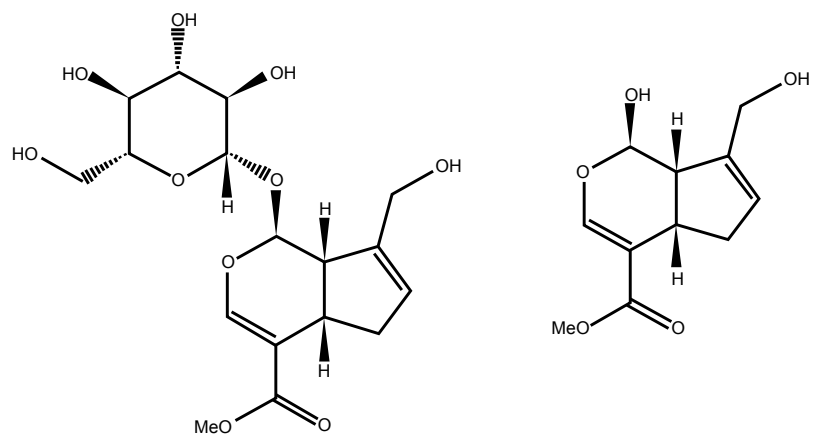

Figure 1: Structure of Geniposide (left) and Genipin (right).

*Corresponding author: Yi-yang $\mathrm{Hu}$, Institute of Liver Diseases, Shuguang Hospital Affiliated to Shanghai University of Traditional Chinese Medicine, 258 Zhangheng Road, Pudong district, Shanghai, China, Tel: 021-20256160; Fax: $021-$ 20256521; E-mail: yyhuliver@163.com

Received March 16 2013; Accepted May 24, 2013; Published May 27, 2013

Citation: Meng S, Peng J, Feng Q, Cao J, Hu Y (2013) The Role of Genipin and Geniposide in Liver Diseases: A Review. Altern Integ Med 2: 117. doi:10.4172/23275162.1000117

Copyright: @ 2013 Meng S, et al. This is an open-access article distributed under the terms of the Creative Commons Attribution License, which permits unrestricted use, distribution, and reproduction in any medium, provided the original author and source are credited. 


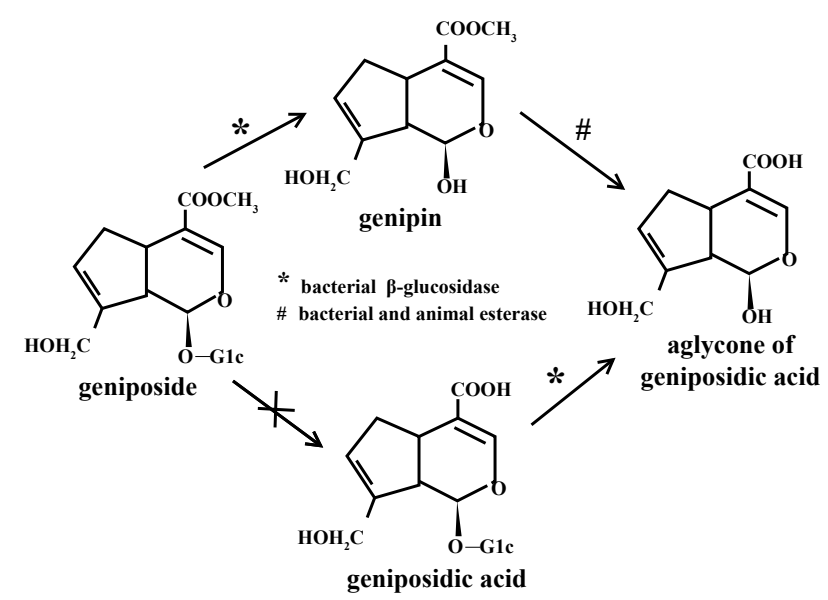

Figure 2: Schematic diagram of intestinal metabolic pathways of geniposide.

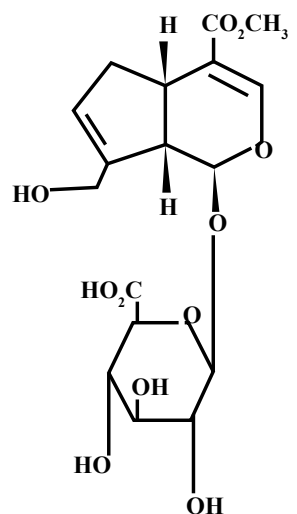

Figure 3: Structure of genipin 1-O- $\beta-D-$ glucuronide.

Geniposide is one of the major iridoid glucosides in Gardenia fruit. It is hydrolyzed in rat intestine by beta-D-glucosidases to form an aglycone genipin compound with choleretic properties [19]. Studies have shown that geniposide is not hydrolyzed by rat liver homogenate, even though it contained beta-D-glucosidase and esterase activities. Thus, beta-D-glucosidases in intestinal bacteria seems to be an absolute requirement for its choleretic action.

Crude extract of Eubacterium spp. A-44 is a human intestinal anaerobe that has been shown to hydrolyze geniposide. The human anaerobe Ruminococcus spp. PO1-3, does not share this property, even though both extracts share beta-D-glucosidase activity for p-nitrophenyl beta-D-glucopy-ranoside. Moreover, only one of its three beta-D-glucosidases from Eubacterium spp. A-44 and neither of the two beta-D-glucosidases from Ruminococcus spp PO1-3 hydrolyzed geniposide to genipin. Carboxylesterases from Eubacterium spp. A-44 in pig liver were unable to hydrolyze geniposide to geniposidic acid, but they did hydrolyze genipin to an aglycone of geniposidic acid. These findings indicate that geniposide is first hydrolyzed to genipin by beta- $\mathrm{D}$-glucosidases, and is subsequently hydrolyzed to the aglycone of geniposidic acid by esterases. Thus, following oral administration of geniposide, genipin is produced in the intestine, absorbed into the circulation and transported to the liver where it acts as a choleretic [7].

In 2004, it was verified that geniposide is converted to genipin by intestinal bacteria and that genipin is transported to the liver via portal circulation and subjected to conjugation (mainly with glucuronides). Thin-layer and/or high performance liquid chromatography (HPLC) indicates that about $20 \%$ of infused genipin is secreted into the bile as the main metabolite 1-O- $\beta$-D-glucuronide (Figure 3 ). Unconjugated genipin accounts for only $2 \%$ of the concentration of genipin-1-O- $\beta$ $\mathrm{D}$-glucuronide. The other unidentified metabolites are present in bile in small amounts [27]. Genipin sulfate was identified as the major metabolite in the circulation following oral administration of genipin or Gardenia fruit decoction to rats. The parent forms of genipin and geniposide were undetectable [28].

\section{Effects on Liver Disease}

\section{Chronic liver injury}

Chronic liver injury is a common condition associated with various liver diseases, which often progress to fibrosis, cirrhosis, or even hepatocellular carcinoma [29].

Kang et al. [9] investigated the effects of geniposide and $G$ jasminoides crude fruit extract on liver cytochrome P-450 (P-450)dependent mono-oxygenases, glutathione and glutathione S-transferase in rats treated orally with the iridoid glycoside or fruit extract for 4 days. Both treatments decreased serum urea nitrogen levels and increased the liver to body weight ratio. Total hepatic glutathione content and hepatic cytosolic glutathione S-transferase activity were also increased.

Geniposide and G. jasminoides decreased cytochrome P-450 levels and reduced benzo-[a]-pyrene hydroxylation, 7-ethoxycoumarin $\mathrm{O}$-deethylation, and erythromycin $\mathrm{N}$-demethylation activity in liver microsomes. However, there was no effect on aniline hydroxylation activity. Neither product had any effect on glutathione content or monooxygenase activity in kidney microsomes. Immunoblotting analyses of liver microsomal proteins using mouse monoclonal antibody 2-13-1 to rat P4503A1/2 revealed that geniposide and G. jasminoides crude extract decreased the intensity of a cytochrome $\mathrm{P} 450$ 3A-immunorelated protein. These findings suggest that geniposide from G. jasminoides acts by inhibiting a P4503A monooxygenase and the increasing glutathione content in rat liver.

Shang Xintao et al. [30] studied the therapeutic effects of geniposide on chronic liver injury induced by carbon tetrachloride $\left(\mathrm{CCl}_{4}\right)$ in rats. Both $\mathrm{CCl}_{4}$ and soybean oil suspension were fed to rats twice a week for 9 weeks, to produce a model of chronic liver injury. The rats were given different doses of geniposide daily for 4 weeks. Twelve hours after the last dose, AST, ALT, AKP, NO were measured in serum and SOD, MDA, HYP, CAT, and GSH was evaluated in liver tissue. The study reported improvements in pathological indicators of liver injury in serum and liver tissue, at the $100 \mathrm{mg} / \mathrm{kg}$ dose level. These findings provided evidence to suggest that geniposide was effective in preventing chronic liver injury induced by $\mathrm{CCl}_{4}$ in rats.

\section{Acute liver injury}

Acute liver injury is a complex process involving many factors. Its main characteristics are hepatocyte necrosis or apoptosis, hepatocyte degeneration, hepatocyte steatosis, biliary silt lesions and hepatocyte inflammatory reactions.

Yamamoto et al. [31] demonstrated that the Chinese herbal medicine, Inchin-ko-to (ICKT), inhibited hepatocyte apoptosis induced by transforming growth factor beta 1 in vitro. The same workers investigated whether ICKT or its ingredients (genipin) inhibited Fasmediated liver apoptosis in vivo. They found that genipin, an intestinal 
bacterial metabolite of geniposide was a major ingredient in the active principle of ICKT. Genipin was shown to suppress Fas-mediated apoptosis in primary-cultured murine hepatocytes. It also inhibited the activation of caspase 3 and 8 in liver homogenates, and reduced triangle uppsi $(\mathrm{m})$ levels in hepatocytes isolated from Jo2-treated mice. Other studies have shown that genipin enhances resistance to $\mathrm{Ca}^{2+}$ induced MPT in mouse liver mitochondria. Taken together, these findings suggest that the anti-apoptotic activity of genipin is mediated by interference with MPT and that this may be a possible mechanism for the therapeutic effects of ICKT.

In other studies, [32] geniposide suppressed AST and ALT activity and prevented the decreased glutathione (GSH) levels that accompanied administration of $\mathrm{CCl}_{4}$ to mice. These findings suggest that a two-fold biochemical mechanism underlies the hepatic protective effect of geniposide. Geniposide reduces the production of the harmful $\mathrm{CCl}_{3}$ radical by decreasing the activities of CYP450 2E1, and at the same time strengthens the ability of GSH system to eliminate free radicals by increasing the activity of glutathione reductase and glutathione S-transferase.

\section{Alcoholic liver disease}

Alcoholic liver disease (ALD) is responsible for a large proportion of all liver diseases worldwide [33]. Acute alcoholic liver injury is a severe form of acute hepatocyte injury associated with significant morbidity and mortality. Prognostic criteria have been developed to help predict disease severity, but its treatment remains a significant challenge [34].

Fu et al. [35] investigated hepatoprotective effects of geniposide on acute alcoholic liver injury in mice. They showed that geniposide reduced the mortality rate, prolonged survival and decreased serum AST and ALT activity. MDA production in the liver was reduced and pathological changes were less severe. Based on these findings geniposide appears to have a hepatoprotective effect in acute alcoholic liver injury in mice.

\section{Bile secretion, liver injury and cholestasis}

Genipin, the major ingredient in ICKT [7], shows marked choleretic activity [36]. Considerable evidence [36] suggests that genipin exerts its choleretic function in a bile acid-independent way by modulating glutathione (GSH) levels in the liver.

Shoda et al. [27] reported a $230 \%$ increase in bile flow following administration of genipin to rats. Biliary secretion of bilirubin conjugates increased by $513 \%$ and GSH secretion was reduced by $336 \%$. These changes were not present in multidrug resistance-associated protein 2 (Mrp2)-deficient rats. The protein mass of Mrp2 in the canalicular membrane vesicles (CMV), increased following exposure to genipin but there were no corresponding changes in $m$ RNA levels. The same researchers reported that in immunoelectron microscope studies, there was a marked increase in Mrp2 density in the canalicular membrane (CM) and microvilli following exposure of liver tissue section to genipin. These findings suggested that genipin may enhance the bile acid-independent secretory capacity of hepatocytes, by stimulating exocytosis and inserting Mrp2 in the bile canaliculi. Mikami $\mathrm{M}$ et al. [37] showed that genipin increased bile flow and biliary glutathione excretion in a manner that was resistant to inhibition by colchicine. The choleretic effect of genipin was considered to be predominantly due to increased biliary glutathione excretion by genipin, rather than to the biliary excretion of glucuronide. Goto et al. [38] 2010 demonstrated that genipin protected against estradiol-17beta-glucuronide-induced cholestasis. Its mechanism of action in this respect remains unclear, but may result from conformational changes in P-gp and/or from stimulation of Mrp2 insertion into bile canaliculi.

Geniposide has also been shown to have beneficial effects on bile secretion and liver injury. Peng et al. [39] compared the effects of geniposide and crocetin (two main principles from Gardenia jasminiodes Eillis), on bile secretion and liver injury in mice. They found that geniposide (50 and $100 \mathrm{mg} / \mathrm{kg}$ ) significantly increased bile secretion while the same doses of crocetin decreased it. In addition, geniposide decreased serum ALT and AST levels in mice with $\mathrm{CCl}_{4}$ and acetaminophen (AAP)-induced liver injury whereas crocetin had no protective effect. In the same mouse model geniposide and crocetin reduced MDA levels, and decreased GSH and glutathione peroxidase (GSH-Px). Histological degeneration was minimized with geniposide which exerted more significant effects than crocetin. Based on these findings, the authors concluded that geniposide was the chief effective component of Gardenia jasminoides Eillis.

\section{Chronic hepatitis}

Chronic viral hepatitis is a major public health issue worldwide [40]. Mase et al. [41] investigated the effects of the active ingredients of inchinkoto (ICKT) on liver injury and cytokine production in vivo (biochemical markers of liver injury and cytokine levels in serum) and in vitro (cytokine and nitrite production in the cultures of splenocytes and peritoneal macrophages). In these experiments, genipin significantly suppressed IFN-gamma production induced in con A-stimulated splenocyte cultures. This was accompanied by suppression of IL-1beta, IL-6, and IL-12p70 synthesis, together with decreased nitrite release from IFN-gamma-stimulated macrophages. These results suggested that genipin may contribute to the protective effects of ICKT against conA hepatitis by modulating cytokine production. These observations were supported by Zhang et al. [42] who also demonstrated that geniposide exhibited significant anti-HCV entry and anti-infectivity activity.

\section{Liver fibrosis}

Liver fibrosis results from excessive accumulation of extracellular matrix (ECM) proteins, and is a major cause of from chronic liver disease. Advanced hepatic fibrosis induced by chronic liver inflammation eventually progresses to cirrhosis [43-46]. Cirrhosis affects hundreds of millions of patients worldwide [44]. In the USA and Europe, it is the most common nonneoplastic cause of death among hepatobiliary and digestive diseases. The condition is also associated with the development of primary liver cancer [47-49].

Inchin-ko-to (TJ-135) is a herbal medicine used for treatment of icteric patients with cirrhosis. Inao et al. [50] investigated the antifibrogenic activity of TJ-135 in stellate cell activation. Liver fibrosis was induced in rats by repeated injections of $\mathrm{CCl}_{4}$ or pig-serum. Oral administration of TJ-135 reduced mortality and decreased the extent of liver necrosis and fibrosis. Similar improvements were reported in rats given pig-serum. DNA synthesis of stellate cells activated in vitro, after isolation from normal rat liver, was decreased in a doserelated manner after exposure to TJ-135. This was accompanied by a decrease in smooth muscle alpha actin expression and contractility. These changes were not apparent in cells cultured with geniposide, which is an iridoid compound of TJ-135. Genipin markedly decreased stellate cell activation without affecting synthesis of proteins other than collagen. These results indicate that TJ-135 may have a therapeutic role in the treatment of liver fibrosis and portal hypertension. Its effects are 
secondary to suppression of activated hepatic stellate cell function by genipin (the absorbed form of its component).

\section{Nonalcoholic fatty liver disease}

Non-alcoholic fatty liver disease (NAFLD) is a hepatic manifestation of metabolic syndrome and is the most common cause of chronic liver disease [51-56], present in 25 to $50 \%$ of diabetic patients [57]. NAFLD encompasses a continuum of pathological changes. Initially, triglycerides accumulate in hepatocytes causing steatosis. This can lead to steatohepatitis (NASH), which is characterized by chronic inflammation, fibrosis and necrosis [58]. Cirrhosis, develops in $20 \%$ of patients with NASH [59] and is a risk factor for hepatocellular carcinoma (HCC), which is the third most common cause of cancer death worldwide [55,58]. Disturbingly, HCC also can form in the setting of NASH without a background of cirrhosis [60,61]. Lifestyle changes and weight loss are difficult to achieve in most patients, highlighting the urgent need for an effective pharmacologic treatment for NAFLD.

Ma et al. [62] investigated the effects of geniposide during the early phase of fibrogenesis in an animal model of NASH. They showed that geniposide improved liver histology by reducing the elevated liver index (liver weight/body weight), and decreasing serum ALT and AST activity. These changes were accompanied by decreases in total cholesterol, triglycerides and fatty acids in serum and liver. Geniposide also increased serum insulin levels and decreased serum tumor necrosis factor- $\alpha$ levels in high-fat diet rats. Expression of CYP2E1 was reduced and peroxisome proliferator-activated receptor- $\alpha$ (PPAR $\alpha$ ) expression was increased. These changes were thought to be associated with increased superoxide dismutase and decreased malondialdehyde levels in the liver. The underlying mechanism by which geniposide protects against hepatic steatosis may, therefore, be associated with its antioxidant actions its ability to regulate adipocytokine release and normalization of PPARa expression.

Lin et al. [63] investigated the effect of genipin and Vitamin $\mathrm{E}$ (VitE) in non-alcoholic fatty liver disease. They reported that genipin in combination with VitE increased mitochondrial membrane potential and markedly relieved adipose degeneration in liver cells. Shi et al. [64] studied the anti-obesity effects of geniposide in L-monosodium glutamate (MSG)-induced obese mice. In these experiment geniposide inhibited food intake, decreased body weight and reduced blood levels of triglycerides and cholesterol.

Based on the current pre-clinical evidence, Samson and Bajaj [65] have shown that glucagon-like peptide-1(GLP-1) analogues and DPP4 inhibitors can improve hepatic steatosis. It is thought that GLP-1 and its analogues activate multiple hepatocyte signal transduction pathways, with both AMP-activated protein kinase and Akt being proposed as be key players in the prevention of hepatic steatosis. Interestingly, it has been shown that geniposide acts as a novel and selective agonist for GLP-1 receptors (GLP-1R) [63] providing further evidence of its potential role in the treatment of NASH.

\section{Fulminant hepatic failure}

Fulminant hepatic failure is a life-threatening clinical syndrome that results in hepatocyte death. It is induced by viruses, alcohol or hepatotoxic agents. The prognosis is poor, and to date the only effective therapy is liver transplantation. Conventional medical therapies are only effective in about $10 \%$ of patients $[66,67]$.

Genipin has been shown to have marked anti-inflammatory and anti-angiogenic effects and inhibit both lipid peroxidation and nitric oxide production [5]. It also suppresses Fas-induced hepatocyte apoptosis and reduces lethality associated with fulminant hepatic failure [30]. Takeuchi et al. [68] explored the mechanism of action of genipin on acute liver injury and concluded that it improved acute liver dysfunction by suppressing of TNF-alpha production.

Recent studies have shown that genipin, acts as a pharmacological inhibitor of uncoupling protein 2, preventing GalN/LPS-induced ATP reduction, 5'AMP-activated protein kinase, and apoptosis [69] (Figure 4). Kim et al. [70] examined the effects of genipin on d-galactosamine (GalN) and lipopolysaccharide (LPS)-induced hepatic apoptosis and liver failure [71]. Genipin was found to protect against GalN/LPSinduced liver injury, thereby preventing oxidative stress, apoptosis and NF- $\mathrm{kB}$ nuclear translocation, and nuclear p-c-Jun expression. This study provides evidence to suggest that genipin may be useful as a potential pharmacological alternative for the prevention of hepatic failure (Figure 4)

\section{Hepatocellular carcinoma}

Hepatocellular carcinoma (HCC) is an extremely malignant human cancer with high metastatic potential. HCC accounts for over $85 \%$ of all liver cancer cases [72] and is newly diagnosed worldwide in more than half of million people annually [73]. HCC is the fifth most common malignant tumor in men and the seventh most common in women [72]. It is the third most common cause of cancer mortality worldwide with incidence rates increasing annually [74]. Despite the provision of different therapeutic approaches, the prognosis of HCC remains poor due to the high recurrence and metastatic rates $[75,76]$. Currently there are no effective chemotherapeutic agents that are capable of preventing metastasis.

Genipin and geniposide have been shown to induce apoptosis in hepatoma cells Hep3B, cervical cancer cells, HeLa cells, prostate cancer cells PC3 and C6 glioma [77-80]. Previous studies have also reported anti-migration and anti-invasion effects of genipin. Genipin has been shown to suppress alpha-TN4 lens epithelial cells and subconjunctival fibroblast migration induced by TGF- $\beta[81,82]$.

Hsu et al. [17] investigated the antitumor effects geniposide and geniposidic acid in mice and found that both agents decreased damage to the hematologic tissue after high dose irradiation. Wang et al. [83] 2010 investigated the anti-metastatic effect of genipin and found that it suppressed the motility and invasiveness of HepG2 and MHCC97L

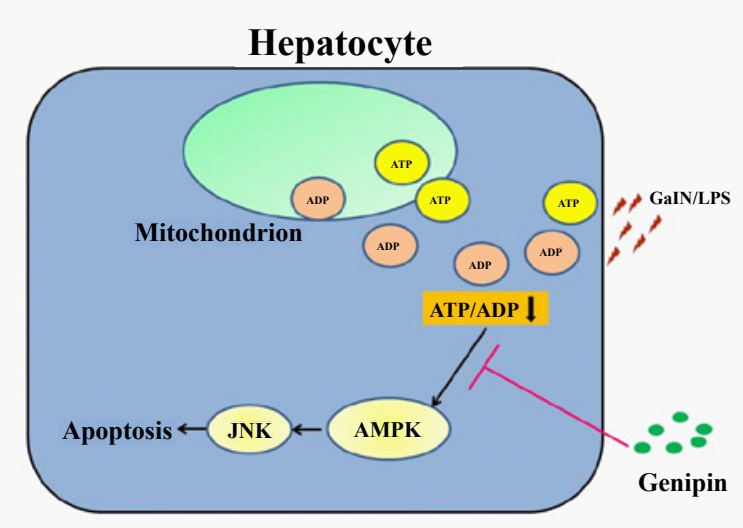

Figure 4: Schematic diagram for genipin inhibition of GalN/LPS-induced hepatocyte apoptosis. 


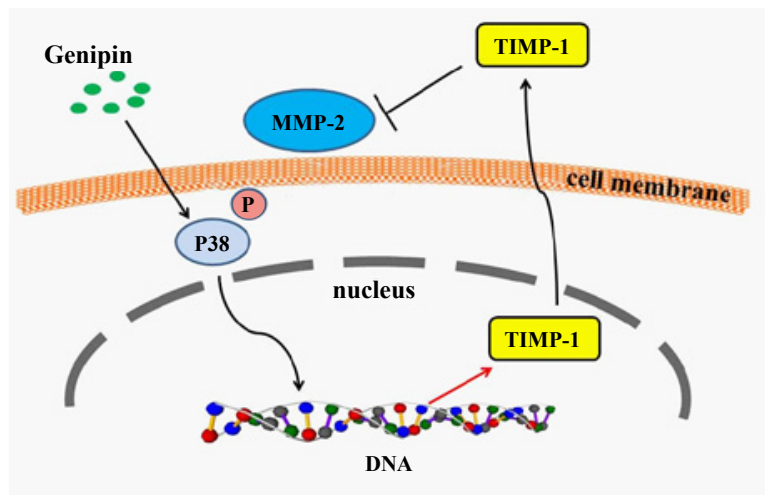

Figure 5: Schematic diagram of the regulatory network involved in the inhibitory effect of genipin on HCC invasion.

at non-toxic doses. These effects were possibly associated with an inhibitory effect of genipin on intracellular MMP-2 activity. They also demonstrated the potential of genipin to suppress HCC metastasis, and indicated that the p38/TIMP-1/MMP-2 pathway may be a key mechanism of this anti-metastatic effect (Figure 5). Kim et al. [77] 2005 demonstrated that genipin induces apoptotic cell death in $\mathrm{FaO}$ rat hepatoma cells and human hepatocarcinoma Hep3B cells, as evidenced by morphological cellular changes, caspase activation and release of cytochrome C. These findings suggest that genipin induced apoptosis in hepatoma cells is mediated by NADPH oxidase-dependent generation of reactive oxygen species (ROS), resulting in downstream activation of c-Jun NH2-terminal kinase (JNK).

\section{Detoxication}

Wang et al. [84] examined the effects of geniposide pretreatment on hepatic aflatoxin B1 (AFB1)-DNA binding and AFB1 hepatotoxicity in rats. Pretreatment with geniposide $10 \mathrm{mg} / \mathrm{kg} /$ day for 3 consecutive days, resulted in suppression of serum marker enzymes (ALT, AST GGT). It was therefore suggested that geniposide possessed chemopreventive effects on the early acute hepatic damage induced by AFB1.

It was further demonstrated that the protective effect of geniposide on AFB1-induced hepatotoxicity in rats may be due to the hepatic tissue defense mechanisms that enhanced S-transferase (GST) activity for AFB1 detoxication and induced gamma-glutamylcysteine synthetase for GSH biosynthesis. Subsequent experiments [85] investigated the effects of geniposide on AFB1-induced DNA repair synthesis and AFB1 biotransformation in cultured rat hepatocytes. Evaluation of unscheduled DNA synthesis (UDS) indicated that geniposide reduced AFB1-induced DNA repair synthesis in a dose-dependent manner in hepatocyte cultures. Geniposide increased AFB1 metabolism and decreased the formation of aflatoxin M1(AFM1). The enzyme activities of glutathione S-transferase (GST) and GSH-peroxidase (GSH-Px) in AFB1-treated hepatocyte cultures were both enhanced in the presence of geniposide. Geniposide reduced AFB1-induced DNA repair synthesis by increasing AFB1 detoxication metabolism. These findings provide a possible mechanism for the chemopreventive activity of geniposide.

Kuo et al. [10] investigated the mechanism of action of geniposide on the GST system. Geniposide-induced GST activity was shown to be dose- and time-dependent, and was found to be mediated via the MEK pathway. These results suggest that geniposide-induced detoxication is mediated by increased transcription of GST M1 and GST M2 resulting in enhanced GST activity. The same workers investigated the signaling pathway of geniposide and demonstrated that geniposide-induced GST activity and the expression of GST M1 and GST M2 resulted from its effects on the MEK-1 pathway which were secondary to activation and increased expression of Ras/Raf/MEK-1 signaling mediators [11].

\section{Toxicity}

Yamano et al. [86] demonstrated that the conversion of geniposide to genipin is causally associated with the hepatotoxicity of geniposide, and that hepatic non-protein sulphydryl groups modulate the extent of toxicity. Sato et al. [87] showed that 3 months ingestion of the gardenia yellow powder containing geniposide $2.783 \%$ (equivalent to intake of $60 \mathrm{mg} / \mathrm{kg} /$ day) was not accompanied by any severe toxic effects.

The $\mathrm{LD}_{50}$ for oral geniposide is $1431.1 \mathrm{mgkg}^{-1}$. Acute toxicity studies indicate that geniposide at doses of $574 \mathrm{mgkg}^{-1}$ and higher are associated with hepatic toxicity in rats. The hepatotoxicity generally appeared 24 to $48 \mathrm{~h}$ after oral administration and was associated with oxidative stress, decreased total superoxide dismutase activity and increased malondialdehyde concentration in rat livers. Subchronic toxicity studies in rats found no evidence of hepatotoxicity at the doses of 24.3 and $72.9 \mathrm{mgkg}^{-1}$ given orally for 90 days. Thus, the acute hepatotoxicity of geniposide at high doses was possibly related with oxidative stress, while geniposide at normal doses of $24.3 \mathrm{mgkg}^{-1}$ were not associated with hepatotoxicity after repeated dosing [88].

Yang et al. [89] studied the hepatotoxic effects in rats with different extracts of Fructus gardeniae. They found that the alcoholic extract and geniposide displayed hepatotoxicity, and that geniposide which was the main extract might be mainly responsible for this. Orally administered genipin $200 \mathrm{mg} / \mathrm{kg}$ resulted in a $78 \%$ mortality rate in rats [27]. Khanal et al. [90] reported that genipin but not geniposide was associated with cytotoxicity. They also demonstrated that human Intestinal microflora (IM) was able to metabolize geniposide genipin, and the resulting biological activity induced apoptosis through ROS/JNK signaling.

Further research is needed to more fully characterize the toxic effects of geniposide and genipin.

\section{Summary and Prospect}

In this review, we describe and analyze the hepatoprotective effects of geniposide and its metabolite, genipin in liver disease. Both compounds exert extensive beneficial effects that offer potential therapeutic benefit to patients with liver disease. Ongoing studies are being conducted to further explore these properties. Further studies will be focused on both short- and long-term effects of geniposide and genipin in the treatment of liver disease and will seek to identify more clearly the complex cellular and biochemical mechanisms that underlie the disease processes.

\section{Acknowledgements}

This project was supported by grants from the National Natural Science Foundation of China (No 81173404); The Innovative Research Team in Shangha Universities, Shanghai Municipal Education Commission; and Leading Academic Discipline of Hepatology of State Administration of TCM China (No: 2010sh)

The authors declare that there is no conflict of interest.

\section{References}

1. Yu Y, Fisher JE, Lillegard JB, Rodysill B, Amiot B, et al. (2012) Cell therapies for liver diseases. Liver Transpl 18: 9-21.

2. Peng $\mathrm{CH}$, Tseng TH, Liu JY, Hsieh YH, Huang CN, et al. (2004) Pentaacetyl geniposide-induced C6 glioma cell apoptosis was associated with the activation of protein kinase C-delta. Chem Biol Interact 147: 287-296. 
Citation: Meng S, Peng J, Feng Q, Cao J, Hu Y (2013) The Role of Genipin and Geniposide in Liver Diseases: A Review. Altern Integ Med 2: 117. doi:10.4172/2327-5162.1000117

3. Wang SC, Liao HJ, Lee WC, Huang CM, Tsai TH (2008) Using orthogonal array to obtain gradient liquid chromatography conditions of enhanced peak intensity to determine geniposide and genipin with electrospray tandem mass spectrometry. J Chromatogr A 1212: 68-75.

4. Miyasita S (1976) A historical study of Chinese drugs for the treatment of Jaundice. Am J Chin Med (Gard City N Y) 4: 239-243.

5. Koo HJ, Song YS, Kim HJ, Lee YH, Hong SM, et al. (2004) Antiinflammatory effects of genipin, an active principle of gardenia. Eur J Pharmacol 495: 201 208.

6. Kimura Y, Okuda H, Arichi S (1982) Effects of geniposide isolated from Gardenia jasminoides on metabolic alterations in high sugar diet-fed rats. Chem Pharm Bull (Tokyo) 30: 4444-4447.

7. Akao T, Kobashi K, Aburada M (1994) Enzymic studies on the animal and intestinal bacterial metabolism of geniposide. Biol Pharm Bull 17: 1573-1576.

8. Yim JS, Kim YS, Moon SK, Cho KH, Bae HS, et al. (2004) Metabolic activities of ginsenoside $\mathrm{Rb} 1$, baicalin, glycyrrhizin and geniposide to their bioactive compounds by human intestinal microflora. Biological \& Pharmaceutical Bulletin 27: 1580-1583.

9. Kang JJ, Wang HW, Liu TY, Chen YC, Ueng TH (1997) Modulation of cytochrome P-450-dependent monooxygenases, glutathione and glutathione S-transferase in rat liver by geniposide from Gardenia jasminoides. Food Chem Toxicol 35: 957-965.

10. Kuo WH, Wang CJ, Young SC, Sun YC, Chen YJ, et al. (2004) Differential induction of the expression of GST subunits by geniposide in rat hepatocytes. Pharmacology 70: 15-22.

11. Kuo WH, Chou FP, Young SC, Chang YC, Wang CJ (2005) Geniposide activates GSH S-transferase by the induction of GST M1 and GST M2 subunits involving the transcription and phosphorylation of MEK-1 signaling in rat hepatocytes. Toxicol Appl Pharmacol 208: 155-162.

12. Koo HJ, Lim KH, Jung HJ, Park EH (2006) Anti-inflammatory evaluation of gardenia extract, geniposide and genipin. J Ethnopharmacol 103: 496-500.

13. Nam KN, Choi YS, Jung HJ, Park GH, Park JM, et al. (2010) Genipin inhibits the inflammatory response of rat brain microglial cells. Int Immunopharmacol 10: 493-499.

14. Okada K, Shoda J, Kano M, Suzuki S, Ohtake N, et al. (2007) Inchinkoto, a herbal medicine, and its ingredients dually exert $\mathrm{mrp} 2 / \mathrm{mrp} 2-$ mediated choleresis and nrf2-mediated antioxidative action in rat livers. American Journal Physiology Gastrointest and Liver Physiology 292: G1450-G1463.

15. Chang WL, Wang HY, Shi LS, Lai JH, Lin HC (2005) Immunosuppressive iridoids from the fruits of Gardenia jasminoides. J Nat Prod 68: 1683-1685.

16. Suzuki Y, Kondo K, Ikeda Y, Umemura K (2001) Antithrombotic effect of geniposide and genipin in the mouse thrombosis model. Planta Med 67: 807810.

17. Hsu HY, Yang JJ, Lin SY, Lin CC (1997) Comparisons of geniposidic acid and geniposide on antitumor and radioprotection after sublethal irradiation. Cancer Lett 113: 31-37.

18. Koo HJ, Lee S, Shin KH, Kim BC, Lim CJ, et al. (2004) Geniposide, an antiangiogenic compound from the fruits of Gardenia jasminoides. Planta Med 70: 467-469.

19. Kim BC, Kim HG, Lee SA, Lim S, Park EH, et al. (2005) Genipin-induced apoptosis in hepatoma cells is mediated by reactive oxygen species/c-Jun $\mathrm{NH}$ 2-terminal kinase-dependent activation of mitochondrial pathway. Biochem Pharmacol 70: 1398-1407.

20. Yamazaki M, Sakura N, Chiba K, Mohri T (2001) Prevention of the neurotoxicity of the amyloid beta protein by genipin. Biol Pharm Bull 24: 1454-1455.

21. Lee P, Lee J, Choi SY, Lee SE, Lee S, et al. (2006) Geniposide from Gardenia jasminoides attenuates neuronal cell death in oxygen and glucose deprivationexposed rat hippocampal slice culture. Biol Pharm Bull 29: 174-176.

22. Tanaka M, Yamazaki M, Chiba K (2009) Neuroprotective action of genipin on tunicamycin-induced cytotoxicity in neuro2a cells. Biol Pharm Bull 32: 12201223.

23. Yamazaki M, Chiba K (2008) Genipin exhibits neurotrophic effects through a common signaling pathway in nitric oxide synthase expressing cells. European Journal of Pharmacology 581: 255-261.
24. Ueno K, Takeda Y, Iwasaki Y, Yoshizaki F (2001) Simultaneous estimation of geniposide and genipin in mouse plasma using high-performance liquid chromatography. Anal Sci 17: 1237-1239.

25. Tseng TY, Tsai TH (2004) Measurement of unbound geniposide in blood, liver, brain and bile of anesthetized rats: an application of pharmacokinetic study and its in?uence on acupuncture. Analytica Chimica Acta 517: 47-52.

26. Ye G, Zhu HY, Zhao HL, Xu B, Huang CG (2006) HPLC method for the determination and pharmacokinetic studies on geniposide in rat serum afte oral administration of traditional Chinese medicinal preparation Yin-Zhi-Ku decoction. Biomed Chromatogr 20: 743-747.

27. Shoda J, Miura T, Utsunomiya H, Oda K, Yamamoto M, et al. (2004) Genipin enhances Mrp2 (Abcc2)-mediated bile formation and organic anion transport in rat liver. Hepatology 39: 167-178.

28. Hou YC, Tsai SY, Lai PY, Chen YS, Chao PD (2008) Metabolism and pharmacokinetics of genipin and geniposide in rats. Food Chem Toxicol 46 2764-2769

29. Saravanan S, Pandikumar P, Pazhanivel N, Paulraj MG, Ignacimuthu S (2013) Hepatoprotective role of Abelmoschus esculentus (Linn.) Moench., on carbon tetrachloride-induced liver injury. Toxicol Mech Methods

30. Shang XT, Zhang L, Zu YG, Cao S (2012) Therapeutic effects of geniposide on chronic liver injury induced by $\mathrm{CCl} 4$ in rats. Pharmacology and Clinics of Chinese Materia Medica 28: 29-31 (in Chinese).

31. Yamamoto M, Miura N, Ohtake N, Amagaya S, Ishige A, et al. (2000) Genipin a metabolite derived from the herbal medicine Inchin-ko-to, and suppression of Fas-induced lethal liver apoptosis in mice. Gastroenterology 118: 380-389.

32. Zhang LM, He KZ, Ren ZJ, Pu Q (2005) Biochemical mechanism of hepatic protective effect of geniposide on liver-injured mice induced by $\mathrm{CCl}_{4}$. Chinese Journal of Applied and Enviromental Biology 11: 669-672 (in Chinese).

33. Wang Y, Hu Y, Chao C, Yuksel M, Colle I, et al. (2013) Role of IRAK-M in alcohol induced liver injury. PLoS One 8: e57085

34. Karsan HA, Parekh S (2012) Management of alcoholic hepatitis: Current concepts. World J Hepatol 4: 335-341.

35. Fu T, Pu Q, Tan J (2007) Hepatoprotective effects of geniposide on acute alcoholic liver injury in mice. Pharmacology and Clinics of Chinese Materia Medica 23: 25-27 (in Chinese).

36. Takeda S, Endo T, Aburada M (1981) Pharmacological studies on iridoid compounds. III. The choleretic mechanism of iridoid compounds. J Pharmacobiodyn 4: 612-623.

37. Mikami M, Takikawa H (2008) Effect of genipin on the biliary excretion of cholephilic compounds in rats. Hepatol Res 38: 614-621.

38. Goto H, Takikawa H (2010) Effect of genipin on cholestasis induced by estradiol-17beta-glucuronide and lithocholate-3-O-glucuornide in rats. Hepato Res 40: 524-529.

39. Peng J, Qian ZY, Liu TZ (2003) Comparative studies on hepatic protective and choleretic effect of geniposide and crocetin. Chinese Journal of New Drugs 12 105-108 (in Chinese)

40. Lemoine M, Nayagam S, Thursz M (2013) Viral hepatitis in resource-limited countries and access to antiviral therapies: current and future challenges. Future Virol 8: 371-380

41. Mase A, Makino B, Tsuchiya N, Yamamoto M, Kase Y, et al. (2010) Active ingredients of traditional Japanese (kampo) medicine, inchinkoto, in murine concanavalin A-induced hepatitis. J Ethnopharmacol 127: 742-749.

42. Zhang H, Rothwangl K, Mesecar AD, Sabahi A, Rong L, et al. (2009) Lamiridosins, hepatitis $\mathrm{C}$ virus entry inhibitors from Lamium album. J Nat Prod 72: $2158-2162$

43. Han KH, Yoon KT (2008) New diagnostic method for liver fibrosis and cirrhosis. Intervirology 51 Suppl 1: 11-16

44. Friedman SL (2003) Liver fibrosis--from bench to bedside. J Hepatol 38 Supp 1: S38-S53.

45. Ginès $P$, Cárdenas A, Arroyo V, Rodés J (2004) Management of cirrhosis and ascites. N Engl J Med 350: 1646-1654.

46. Pinzani M, Rombouts K, Colagrande S (2005) Fibrosis in chronic live diseases: diagnosis and management. J Hepatol 42 Suppl: S22-S36. 
Citation: Meng S, Peng J, Feng Q, Cao J, Hu Y (2013) The Role of Genipin and Geniposide in Liver Diseases: A Review. Altern Integ Med 2: 117. doi:10.4172/2327-5162.1000117

47. El-Serag HB (2002) Hepatocellular carcinoma and hepatitis C in the United States. Hepatology 36: S74-S83.

48. Befeler AS, Di Bisceglie AM (2002) Hepatocellular carcinoma: diagnosis and treatment. Gastroenterology 122: 1609-1619.

49. Pungpapong S, Kim WR, Poterucha JJ (2007) Natural history of hepatitis B virus infection: an update for clinicians. Mayo Clin Proc 82: 967-975.

50. Inao M, Mochida S, Matsui A, Eguchi Y, Yulutuz Y, et al. (2004) Japanese herbal medicine Inchin-ko-to as a therapeutic drug for liver fibrosis. J Hepatol 41: 584-591.

51. Iwasaki T, Yoneda M, Inamori M, Shirakawa J, Higurashi T, et al. (2011) Sitagliptin as a novel treatment agent for non-alcoholic Fatty liver disease patients with type 2 diabetes mellitus. Hepatogastroenterology 58: 2103-2105.

52. Sumida $\mathrm{Y}$, Yoneda M, Hyogo $\mathrm{H}$, Yamaguchi $\mathrm{K}$, Ono M, et al. (2011) A simple clinical scoring system using ferritin, fasting insulin, and type IV collagen 7S for predicting steatohepatitis in nonalcoholic fatty liver disease. J Gastroenterol 46: 257-268.

53. Eguchi $\mathrm{Y}$, Hyogo H, Ono M, Mizuta T, Ono N, et al. (2012) Prevalence and associated metabolic factors of nonalcoholic fatty liver disease in the general population from 2009 to 2010 in Japan: a multicenter large retrospective study. J Gastroenterol 47: 586-595.

54. Sumida $\mathrm{Y}$, Yoneda M, Hyogo $\mathrm{H}$, Itoh $\mathrm{Y}$, Ono M, et al. (2012) Validation of the FIB4 index in a Japanese nonalcoholic fatty liver disease population. BMC Gastroenterol 12: 2

55. Krawczyk M, Bonfrate L, Portincasa P (2010) Nonalcoholic fatty liver disease. Best Pract Res Clin Gastroenterol 24: 695-708.

56. Starley BQ, Calcagno CJ, Harrison SA (2010) Nonalcoholic fatty liver disease and hepatocellular carcinoma: a weighty connection. Hepatology 51: 18201832.

57. Mazza A, Fruci B, Garinis GA, Giuliano S, Malaguarnera R, et al. (2012) The role of metformin in the management of NAFLD. Exp Diabetes Res 2012: 716404.

58. Zhang ZJ, Zheng ZJ, Shi R, Su Q, Jiang Q, et al. (2012) Metformin for liver cancer prevention in patients with type 2 diabetes: a systematic review and meta-analysis. J Clin Endocrinol Metab 97: 2347-2353.

59. Krawczyk M, Bonfrate L, Portincasa $P$ (2010) Nonalcoholic fatty liver disease. Best Pract Res Clin Gastroenterol 24: 695-708.

60. Baffy G, Brunt EM, Caldwell SH (2012) Hepatocellular carcinoma in nonalcoholic fatty liver disease: an emerging menace. J Hepatol 56: 1384-1391.

61. Lai SW, Chen PC, Liao KF, Muo CH, Lin CC, et al. (2012) Risk of hepatocellular carcinoma in diabetic patients and risk reduction associated with anti-diabetic therapy: a population-based cohort study. Am J Gastroenterol 107: 46-52.

62. Ma T, Huang C, Zong G, Zha D, Meng X, et al. (2011) Hepatoprotective effects of geniposide in a rat model of nonalcoholic steatohepatitis. J Pharm Pharmacol 63: 587-593.

63. Lin L, Guan X, Wang L, Tang $Y(2010)$ [Influence of genipin and vitamin E on UCP2 and other correlation factors in non-alcoholic fatty liver disease]. Sheng Wu Yi Xue Gong Cheng Xue Za Zhi 27: 1327-1331.

64. Shi L, Sun J, Li L (2011) Antiobesity Effects of Geniposide on Monosodium Glutamate-induced Obese Mice. China Pharmacy 22: 3671-3673(in Chinese).

65. Samson SL, Bajaj M (2013) Potential of incretin-based therapies for nonalcoholic fatty liver disease. J Diabetes Complications.

66. Liu J, Zheng X, Yin F, Hu Y, Guo L, et al. (2006) Neurotrophic property of geniposide for inducing the neuronal differentiation of PC12 cells. Int J Dev Neurosci 24: 419-424.

67. Shakil AO, Kramer D, Mazariegos GV, Fung JJ, Rakela J (2000) Acute liver failure: clinical features, outcome analysis, and applicability of prognostic criteria. Liver Transpl 6: 163-169.

68. Takeuchi S, Goto T, Mikami K, Miura K, Ohshima S, et al. (2005) Genipin prevents fulminant hepatic failure resulting in reduction of lethality through the suppression of TNF-alpha production. Hepatology Research 33: 298-305.

69. Shang Y, Liu Y, Du L, Wang Y, Cheng X, et al. (2009) Targeted expression of uncoupling protein 2 to mouse liver increases the susceptibility to lipopolysaccharide/ galactosamine-induced acute liver injury. Hepatology 50 : 1204-1216.
70. Kim SJ, Kim JK, Lee DU, Kwak JH, Lee SM (2010) Genipin protects lipopolysaccharide-induced apoptotic liver damage in D-galactosaminesensitized mice. Eur J Pharmacol 635: 188-193.

71. Lin BR, Yu CJ, Chen WC, Lee HS, Chang HM, et al. (2009) Green tea extract supplement reduces D-galactosamine-induced acute liver injury by inhibition of apoptotic and proinflammatory signaling. J Biomed Sci 16: 35.

72. El-Serag HB (2011) Hepatocellular carcinoma. N Engl J Med 365: 1118-1127.

73. Ferlay J, Bray F, Pisani P, Parkin DM (2000) Cancer incidence, mortality and prevalence worldwide, version 1.0. 2000: International Agency for Research on Cancer Base no. 5. Lyon, France: IARC Press.

74. Altekruse SF, McGlynn KA, Reichman ME (2009) Hepatocellular carcinoma incidence, mortality, and survival trends in the United States from 1975 to 2005. J Clin Oncol 27: 1485-1491.

75. Wang N, Feng Y, Lau EP, Tsang C, Ching Y, et al. (2010) F-actin reorganization and inactivation of rho signaling pathway involved in the inhibitory effect of Coptidis Rhizoma on hepatoma cell migration. Integr Cancer Ther 9: 354-364.

76. Kanai T, Hirohashi S, Upton MP, Noguchi M, Kishi K, et al. (1987) Pathology of small hepatocellular carcinoma. A proposal for a new gross classification. Cancer 60: 810-819.

77. Kim BC, Kim HG, Lee SA, Lim S, Park EH, et al. (2005) Genipin-induced apoptosis in hepatoma cells is mediated by reactive oxygen species/c-Jun $\mathrm{NH} 2$-terminal kinase-dependent activation of mitochondrial pathway. Biochem Pharmacol 70: 1398-1407.

78. Cao H, Feng Q, Xu W, Li X, Kang Z, et al. (2010) Genipin induced apoptosis associated with activation of the c-Jun NH2-terminal kinase and p53 protein in HeLa cells. Biol Pharm Bull 33: 1343-1348.

79. Hong HY, Kim BC (2007) Mixed lineage kinase 3 connects reactive oxygen species to c-Jun NH2-terminal kinase-induced mitochondrial apoptosis in genipin-treated PC3 human prostate cancer cells. Research Communications 362: 307-312.

80. Peng $\mathrm{CH}$, Huang CN, Hsu SP, Wang CJ (2007) Penta-acetyl geniposideinduced apoptosis involving transcription of NGF/p75 via MAPK-mediated AP-1 activation in C6 glioma cells. Toxicology 238: 130-139.

81. Kitano A,Saika S, Yamanaka O, Ikeda K, Reinach PS, et al. (2006) Genipin suppresses subconjunctival fibroblast migration, proliferation and myofibroblast transdifferentiation. Ophthalmic Research 38: 355-360.

82. Kitano A, Saika S, Yamanaka O, Reinach PS, Ikeda K, et al. (2006) Genipin suppression of fibrogenic behaviors of the alpha-TN4 lens epithelial cell line. $J$ Cataract Refract Surg 32: 1727-1735.

83. Wang N, Zhu M, Tsao SW, Man K, Zhang Z, et al. (2012) Up-regulation of TIMP-1 by genipin inhibits MMP-2 activities and suppresses the metastatic potential of human hepatocellular carcinoma. PLoS One 7: e46318.

84. Wang CJ, Wang SW, Lin JK (1991) Suppressive effect of geniposide on the hepatotoxicity and hepatic DNA binding of aflatoxin B1 in rats. Cancer Let 60: 95-102.

85. Wang SW, Lai CY, Wang CJ (1992) Inhibitory effect of geniposide on aflatoxin B1-induced DNA repair synthesis in primary cultured rat hepatocytes. Cancer Lett 65: 133-137.

86. Yamano T, Tsujimoto Y, Noda T, Shimizu M, Ohmori M, et al. (1990) Hepatotoxicity of geniposide in rats. Food Chem Toxicol 28: 515-519.

87. Sato S, Kitamura H, Chino M, Takei Y, Hiruma M, et al. (2007) A 13-week oral dose subchronic toxicity study of gardenia yellow containing geniposide in rats. Food Chem Toxicol 45: 1537-1544.

88. Ding Y, Zhang T, Tao JS, Zhang LY, Shi JR, et al. (2012) Potential hepatotoxicity of geniposide, the major iridoid glycoside in dried ripe fruits of Gardenia jasminoides (Zhi-zi). Nat Prod Res. 
Citation: Meng S, Peng J, Feng Q, Cao J, Hu Y (2013) The Role of Genipin and Geniposide in Liver Diseases: A Review. Altern Integ Med 2: 117. doi:10.4172/2327-5162.1000117

Page 8 of 8

89. Yang HJ, Fu MH, Wu ZL, Liang RX, Huang LQ, et al. (2006) Experimental studies on hepatotoxicity of rats induced by Fructus Gardeniae. Zhongguo Zhong Yao Za Zhi 31: 1091-1093.
90. Khanal T, Kim HG, Choi JH, Do MT, Kong MJ, et al. (2012) Biotransformation of geniposide by human intestinal microflora on cytotoxicity against HepG2 cells. Toxicol Lett 209: 246-254. 